\title{
A Response to: Letter to the Editor Regarding "Critical Differences Between Dietary Supplement and Prescription Omega-3 Fatty Acids: a Narrative Review"
}

\author{
Daniel E. Hilleman - Barbara S. Wiggins $\cdot$ Michael B. Bottorff
}

Received: June 12, 2020 / Published online: July 9, 2020

(C) The Author(s) 2020

Keywords: Cardiovascular disease; Dietary supplements; Docosahexaenoic acid; Eicosapentaenoic acid; Fish oils; Hypertriglyceridemia; Icosapent ethyl; Omega3-fatty acids

\section{Dear Editor,}

Thank you for the opportunity to respond to the letter from Drs. Bannenberg and Rice. While their comments may be well intentioned, we respectfully disagree with their assertions and have detailed our reasoning below based on a critical evaluation of the published data and methods.

A thorough review of the ingredients in the three widely used dietary fish oil supplements tested in the Mason and Sherratt article [1] did not include any artificial flavors or colors that would interfere with colorimetric assays used

Digital Features To view digital features for this article go to https://doi.org/10.6084/m9.figshare.12497432.

\footnotetext{
D. E. Hilleman ( $\square)$

Creighton University, Omaha, NE, USA

e-mail: danielhilleman@creighton.edu

B. S. Wiggins

Medical University of South Carolina, Charleston, SC, USA

M. B. Bottorff

Department of Pharmacy Practice, Manchester

University, Fort Wayne, IN, USA
}

for measuring certain, but not all, oxidation products such as anisidine. Claims to the contrary by the authors of the letter are false unless the manufacturers of the products are deliberately misleading consumers by not stating otherwise.

Additionally, Mason and Sherratt [1] measured more than one oxidation product, all consistently exceeding levels set by the industry. Beyond these oxidation products, this study reported that the dietary fish oil supplements contained substantial levels of oils that may actually be harmful for patients with cardiovascular risk, especially various saturated fats. This resulted in attenuated biological activity with respect to inhibition of lipoprotein oxidation as measured in vitro.

It was erroneously stated by Drs. Bannenberg and Rice that the finding of excessive oxidation products in these widely used fish oil supplements was due to normalization procedures. A careful review of the data reported by Mason and Sherratt [1] demonstrates that this is an unfounded concern based on the actual measurements of specific lipid oxidation products that clearly exceeded GOED-based standards. Thus, the findings of excessive oxidation reported by Mason and Sherratt [1] were conducted using appropriate tests, highly reproducible, and consistent with findings from a number of independent academic laboratories. 
Furthermore, the Bannenberg et al. study does not adequately replicate the Albert et al. study [2]. First, just over half of the products overlapped between studies, and the products that did overlap had lower peroxide values than those that were unique to the Albert study. This suggests that the Bannenberg et al. study exhibited product selection bias toward those with lower levels of oxidation. Second, the Bannenberg et al. study [3] was conducted 2 years after the Albert et al. study [2]; the samples therefore reflect different batches of fish caught in different seasons. One specific product had substantially different content between studies, suggesting that the manufacturer changed the oil product within their brand. Importantly, the Albert et al. study protocol [2] had rules governing consistent selection of products that accounted for "best before" dates, while the Bannenberg et al. [3] study did not. As a result, the latter may have selected products that were more recently manufactured and less oxidized.

Perhaps most critically, the Bannenberg et al. study [3] did not provide an adequate description of how products were selected to be tested between the different laboratories. This resulted in increased heterogeneity between product testing and laboratory utilization, as some products were tested multiple times and some laboratories were hardly used. This strongly raises the possibility of excluded data and/or other sources of biases, negatively influencing the conclusions drawn from Bannenberg et al. [3].

The Albert et al. analysis [2] was carefully conducted to avoid inadvertent oxidation of the oils on the day of testing; the claim that the oils could have oxidized during analysis is unfounded. N-3 polyunsaturated fatty acid (PUFA)-rich oils, while chemically unstable, do not oxidize quickly enough, even under severe conditions, for inadvertent oxidation during the analysis phase to explain the lack of compliance for quality. For example, Ottestad et al. [4] showed that even where oil was enriched with oxygen to cause oxidation, oxidation occurred slowly, increasing by $14 \mathrm{meq} / \mathrm{kg}$ over a period of 21 days. The methodology used for quantitative fatty acid analysis by Albert et al. [2] is well established, incorporating internal standards, quality controls, and specific calibration curves generated from a genuine fatty acid mixture, as first cited by Lepage and Roy [5]. Albert et al. [2] compared the indices of oxidation to the recommendations of industry and GOED, as the level of oxidation required to change health effects is not well investigated.

In summary, we have carefully considered the totality of available scientific evidence comparing the differences between dietary supplements and prescription fish oils and have accurately presented the information in our narrative review. We maintain that the Albert et al. study [2] is credible and appropriately portrayed in the narrative review, and thus, we strongly disagree with the views shared by Drs. Bannenberg and Rice. This article is based on previously conducted studies and does not contain any studies with human participants or animals performed by any of the authors.

\section{ACKNOWLEDGEMENTS}

Funding. No Rapid Service Fee was received by the journal for the publication of this article.

Authorship. All named authors meet the International Committee of Medical Journal Editors (ICMJE) criteria for authorship for this article, take responsibility for the integrity of the work as a whole, and have given their approval for this version to be published.

Medical Writing and Editorial Assistance. Editorial support for this letter was provided by Rohan Shah, PhD, of Peloton Advantage, an OPEN Health company, and funded by Amarin Pharma, Inc. The statements and opinions in this letter are those of the authors and not any other individual or entity.

Disclosures. Daniel E. Hilleman has served on the speakers bureau for Amgen and Amarin and as a consultant for Heron Therapeutics. Barbara S. Wiggins has nothing to disclose. Michael B. Bottorff has served on the speakers bureau for Pfizer and BMS and as a consultant for Medisync. 
Compliance with Ethics Guidelines. This article is based on previously conducted studies and does not contain any studies with human participants or animals performed by any of the authors.

Data Availability. Data sharing is not applicable to this article as no datasets were generated or analyzed during the current study.

Open Access. This article is licensed under a Creative Commons Attribution-NonCommercial 4.0 International License, which permits any non-commercial use, sharing, adaptation, distribution and reproduction in any medium or format, as long as you give appropriate credit to the original author(s) and the source, provide a link to the Creative Commons licence, and indicate if changes were made. The images or other third party material in this article are included in the article's Creative Commons licence, unless indicated otherwise in a credit line to the material. If material is not included in the article's Creative Commons licence and your intended use is not permitted by statutory regulation or exceeds the permitted use, you will need to obtain permission directly from the copyright holder. To view a copy of this licence, visit http://creativecommons.org/licenses/bync/4.0/.

\section{REFERENCES}

1. Mason RP, Sherratt SCR. Omega-3 fatty acid fish oil dietary supplements contain saturated fats and oxidized lipids that may interfere with their intended biological benefits. Biochem Biophys Res Commun. 2017;483:425-9.

2. Albert BB, Derraik JG, Cameron-Smith D, et al. Fish oil supplements in New Zealand are highly oxidised and do not meet label content of n-3 PUFA. Sci Rep. 2015;5:7928.

3. Bannenberg G, Mallon C, Edwards H, et al. Omega-3 long-chain polyunsaturated fatty acid content and oxidation state of fish oil supplements in New Zealand. Sci Rep. 2017;7:1488.

4. Ottestad I, Vogt G, Retterstøl K, et al. Oxidised fish oil does not influence established markers of oxidative stress in healthy human subjects: a randomised controlled trial. Br J Nutr. 2012;108(2):315-26.

5. Lepage G, Roy CC. Direct transesterification of all classes of lipids in a one-step reaction. J Lipid Res. 1986;27(1):114-20. 